\title{
Cardiac arrhythmias 48 hours before, during, and 48 hours after discharge from hospital following acute myocardial infarction
}

\author{
G W MORRISON, E B KUMAR, R W PORTAL, CLIVE P ABER \\ From the Department of Cardiology, Kingston General Hospital, Hull
}

SUMMARY The cardiac rate and rhythm were studied by 24-hour ambulatory electrocardiographic recording in 44 patients before, during, and after being discharged from hospital following an acute myocardial infarction. The first recordings were started 48 hours before discharge, the second on the morning of the day of discharge, and the third 48 hours after discharge (at home). While in hospital and after returning home the heart rate fell during sleep but there was no diurnal variation in the frequency of ventricular extrasystoles. Daytime heart rate and both the frequency and grade (severity) of ventricular arrhythmias were significantly raised 48 hours after discharge. The frequency of ventricular extrasystoles during sleep was also increased in the 48 hours post-discharge recording. Rises in heart rate and frequency and severity of ventricular extrasystoles were observed on the morning of the day of discharge, increasing up to the time of leaving hospital, but during the journey home they all diminished. No relation was found between ventricular arrhythmias during early convalescence and (i) ventricular arrhythmias during the acute phase of acute myocardial infarction (including ventricular fibrillation); (ii) peak aspartate aminotransferase; (iii) the level of anxiety; or (iv) the personality type. Six patients taking beta-blocking drugs behaved similarly. Five patients taking anxiolytic drugs had significantly raised frequency of ventricular extrasystoles during each 24-hour electrocardiogram.

In spite of the above findings, at the time of leaving hospital after acute myocardial infarction there does not appear to be a serious risk from the development of major cardiac arrhythmias.

The acute phase of myocardial infarction may be complicated by sudden arrhythmic death, often preceded by "warning" ventricular arrhythmias. ${ }^{12}$ Less attention has been given to the convalescent phase of acute myocardial infarction, though patients remain at risk from serious cardiac arrhythmias and sudden death. ${ }^{3-8}$ Some patients die within weeks of discharge from hospital ${ }^{10}$ and a relation has been observed between early post-hospital death and the occurrence of arrhythmias while in hospital ${ }^{81112}$

On the day of discharge from hospital there might be heightened stress ${ }^{13}$ and a corresponding increased incidence of, and risk from, arrhythmias. ${ }^{14}$ This study was therefore designed to determine whether hospital discharge was associated with increased ventricular arrhythmias.

*Present address: Department of Cardiology, St James Hospital, Leeds.

Received for publication 12 September 1980

\section{Methods}

The 48 patients studied represent a consecutive series discharged from hospital within three weeks of suffering an acute myocardial infarction. The diagnosis of acute myocardial infarction was made on the basis of a typical history, changes in the electrocardiogram, and raised serum aspartate aminotransferase and/or serum hydroxybutyrate dehydrogenase levels. There were no exclusions before electrocardiographic tape analysis. All patients entered the coronary care unit within 24 hours of the onset of symptoms and usually underwent a 72-hour period of continuous electrocardiographic monitoring. They were then transferred to a general cardiac ward for mobilisation. Most patients were sitting out of bed by the fifth day, freely ambulant by the eighth day, and discharged home between the 10th and 14th days. 
Apart from personal details of each patient, including an assessment of personality type, ${ }^{15}$ a note was made of previous cardiovascular disease and drug treatment on admission. Some measure of the size of the infarct was attempted by determination of the peak serum aspartate aminotransferase. All the data were obtained prospectively, and all patients gave their consent to be included in the study.

Three 24-hour electrocardiographic recordings were made in each patient: (a) hospital recording (starting 48 hours before discharge); (b) peridischarge recording (starting on the morning of the day of discharge); and (c) home recording (starting 48 hours after hospital discharge). The recordings were made on magnetic tape using Medilog Tape Cassette Recorders (Oxford Electronic Instruments Limited, Abingdon, England). Each recording was started as near to 0900 hours as possible. They were played back at $60 \times$ real time using a Medilog 4-24 High Speed Replay Unit (Oxford Electronic Instruments Ltd), and analysis was performed using an automatic high speed electrocardiogram analyser (Reynolds Medical Electronics, Hertford, England). Episodes of the following were noted: sinus tachycardia ( $>120 / \mathrm{min})$; sinus bradycardia $(<45 / \mathrm{min}$ ); supraventricular tachycardia (runs of three or more supraventricular extrasystoles at a rate of more than $100 / \mathrm{min}$ ); atrial fibrillation; ventricular extrasystoles; bigeminy; pairing (two consecutive ventricular extrasystoles); ventricular tachycardia (three or more consecutive ventricular extrasystoles at a rate of $>100 / \mathrm{min}$ ); R-on- $\mathrm{T}$ phenomenon (ratio $R R^{\prime} / \mathrm{QT}<1.0$ ). All tapes were analysed by the same person (GWM) in random sequence, without knowledge of the patient's identity. Each hour of recording (one minute of playback time) was analysed in turn and the hourly counts of each of the above variables were noted.
The maximum severity of ventricular arrhythmias occurring in each hour was graded from 0 to 5 according to the system described by Lown and Wolf ${ }^{16}(0=$ no ventricular extrasystoles; $1=$ unifocal ventricular extrasystoles $<30$ per hour; $2=$ unifocal ventricular extrasystoles $>30$ per hour; $3=$ multifocal ventricular extrasystoles; $4=$ episodes of bigeminy, pairing, or ventricular tachycardia; $5=\mathrm{R}$-on- $\mathrm{T}$ phenomenon). In order to improve the accuracy of ventricular arrhythmia evaluation this analysis was performed visually whenever possible. Heart rate was, however, computed from the automatic hourly QRS count, with check samples of electrocardiographic traces taken at the end of each hour.

During the recordings patients completed diary cards, particularly noting the times of sleeping and waking and, on the day of discharge, the times of leaving the ward and arriving home. When each electrocardiograph tape was collected (GWM and EBK) a short questionnaire was completed with respect to the level of physical activity, frequency of visitors, smoking habits, and drug treatment.

On the morning of the day of discharge each patient was interviewed (GWM or EBK) and asked to grade any feelings of apprehension as "none", "moderate", or "severe". The observer also recorded his assessment of the patient on the same scale. All patients were given a standard briefing by the nursing staff regarding the level of activity they should pursue. They were advised to avoid repetitive stair-climbing and travelling out-ofdoors during the first week after discharge.

Unless stated, the figures represent means ( \pm SEM) and the significance of differences was determined using the paired and unpaired Student's $t$ tests. Correlations were investigated by linear regression analysis.

Table 1 Baseline details of 44 patients

\begin{tabular}{|c|c|c|c|c|c|c|c|}
\hline Men & Women & Mean age $(y)$ & Personality type & Smokers & Previous angina & $\begin{array}{l}\text { Previous acute } \\
\text { myocardial } \\
\text { infarction }\end{array}$ & $\begin{array}{l}\text { Site of acute } \\
\text { myocardial } \\
\text { infarction }\end{array}$ \\
\hline $28(64 \%)$ & $16(36 \%)$ & $59 \cdot 7 \pm 7 \cdot 9$ & $\begin{array}{l}A-11(25 \%) \\
B-33(75 \%)\end{array}$ & $26(59 \%)$ & $22(50 \%)$ & $8(18 \%)$ & $\begin{array}{l}A-18(41 \%) \\
\text { I }-17(39 \%) \\
\text { In- } 9(20 \%)\end{array}$ \\
\hline $\begin{array}{l}\text { Mean peak } \\
\text { serum aspartate } \\
\text { aminotransferase } \\
\text { (units) } \star \star\end{array}$ & $\begin{array}{l}\text { Mean maximum } \\
\text { heart rate } \\
\text { (bpm) }\end{array}$ & $\begin{array}{l}\text { Mean minimum } \\
\text { systolic blood } \\
\text { pressure } \\
(\mathrm{mmHg})\end{array}$ & $\begin{array}{l}\text { Ventricular } \\
\text { extrasystoles } \\
>30 / \mathrm{min}\end{array}$ & $\begin{array}{l}\text { Incidence of } \\
\text { ventricular } \\
\text { fibrillation }\end{array}$ & $\begin{array}{l}\text { Incidence of } \\
\text { heart failure }\end{array}$ & $\begin{array}{l}\text { Incidence of } \\
\text { cardiogenic } \\
\text { shock }\end{array}$ & $\begin{array}{l}\text { Mean duration of } \\
\text { hospital stay (d) }\end{array}$ \\
\hline $205 \pm 126$ & $98 \cdot 6 \pm 16.9$ & $102 \cdot 2 \pm 14 \cdot 7$ & $16(36 \%)$ & $5(11 \%)$ & $14(32 \%)$ & $4(9 \%)$ & $12 \cdot 3 \pm 3.6$ \\
\hline
\end{tabular}

Figures given are means $\pm \mathrm{SD}$.

$\star A$, anterior; $I$, inferior; In, indeterminate.

$\star \star$ Normal range for serum aspartate aminotransferase $20-40$ units. 


\section{Results}

One hundred and thirty-seven 24-hour electrocardiograms were made in $\mathbf{4 8}$ patients. Forty-two of the recordings were not satisfactory, however, either because of electrocardiographic artefact or temporary signal loss. After exclusion of these, there were 94 recordings from 44 patients (28 men and 16 women) available for complete analysis. Thirty-four recordings were made in hospital, 28 on the day of discharge, and 32 at home. In 17 patients satisfactory recordings were available from all three stages. The mean $( \pm S D)$ age of the patients was $59 \cdot 7 \pm 7.9$ years and the mean $( \pm S D)$ duration of hospital stay was $12.3 \pm 3.6$ days. Other details of the 44 patients are given in Table 1 .

At the time of discharge patients were taking the following drugs: diuretics (21); digoxin (five); beta-blockers (six); disopyramide (three); diazepam (five).

\section{(1) CORRELATIONS OF FINDINGS IN TAPES RECORDED AT DIFFERENT TIMES}

The results from all the tapes were first pooled. The mean heart rate in the 44 patients was $77 \cdot 7 \pm 1 \cdot 5$ $\mathrm{bpm}$. The average frequency of ventricular extrasystoles was $30.9 \pm 12.0 \mathrm{bph}$, with an average grade of $1 \cdot 14 \pm 0 \cdot 13$. In the 17 patients in whom all three recordings were satisfactory there were high correlations of the average heart rate, frequency of ventricular extrasystoles, and grade of ventricular arrhythmias between the three tapes. For heart rate the correlation coefficient was best between the hospital and the peri-discharge recordings $(r=$ $0.9509 ; \mathrm{p}<0.001)$ and least good between the hospital and home recordings $(r=0.9246 ; p<0.001)$. For frequency of ventricular extrasystoles the corresponding correlation coefficients were 0.9994 $(p<0.001)$ and $0.7838(p<0.01)$ and for grade of ventricular arrhythmias they were $0.7622(\mathrm{p}<0.01$ and $0.7481(p<0.01)$, respectively. Throughout the tapes the average frequency of ventricular extrasystoles and grade of ventricular arrhythmias were highly correlated with each other $(r=0.6303$; $\mathrm{p}<0.001)$.

(2) DIURNAL VARIATION

A fall in heart rate during sleep was observed both in hospital and at home (Fig. 1 and 2). For example, at home the average heart rate over the period 2400

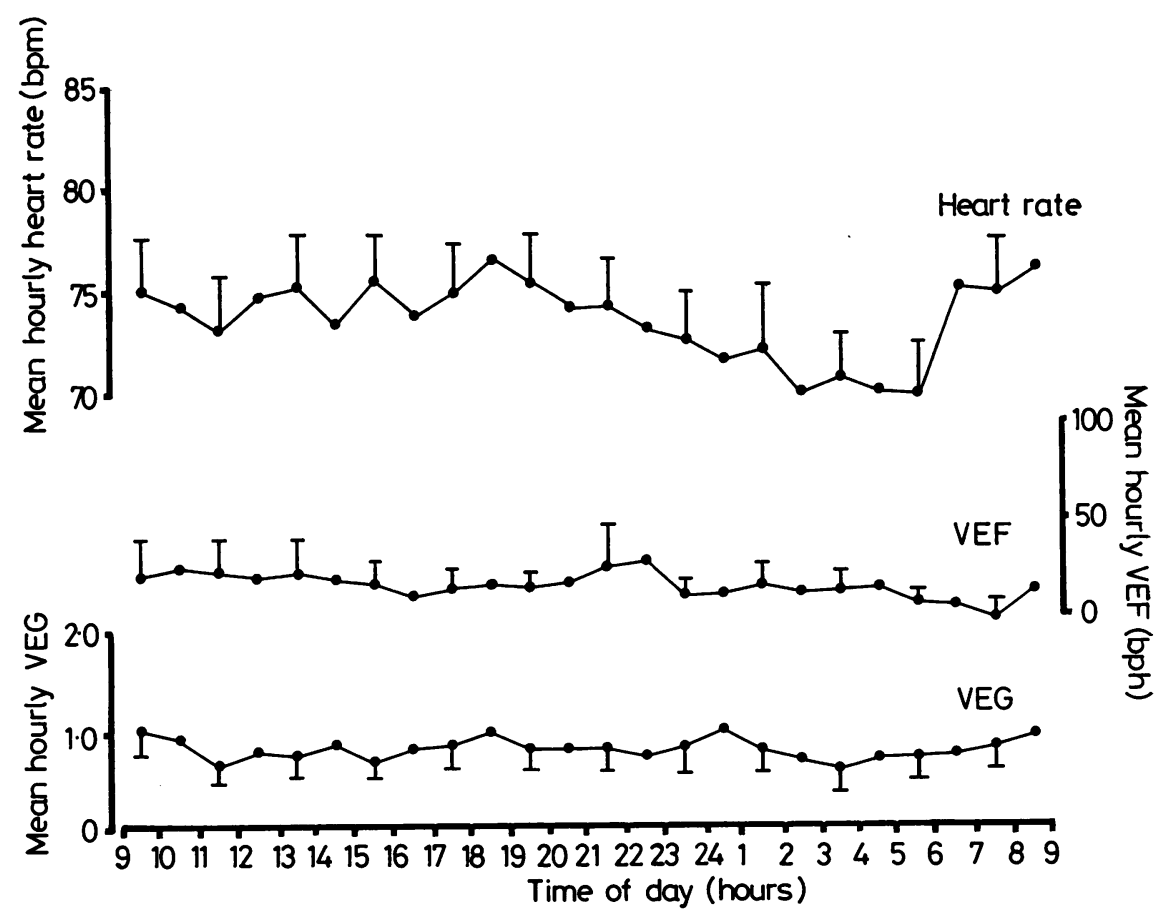

Fig. 1 Diurnal variation of heart rate, frequency of ventricular extrasystoles (VEF), and grade (severity) of ventricular arrhythmias (VEG) during hospital recordings (34 patients; bars represent SEM). 


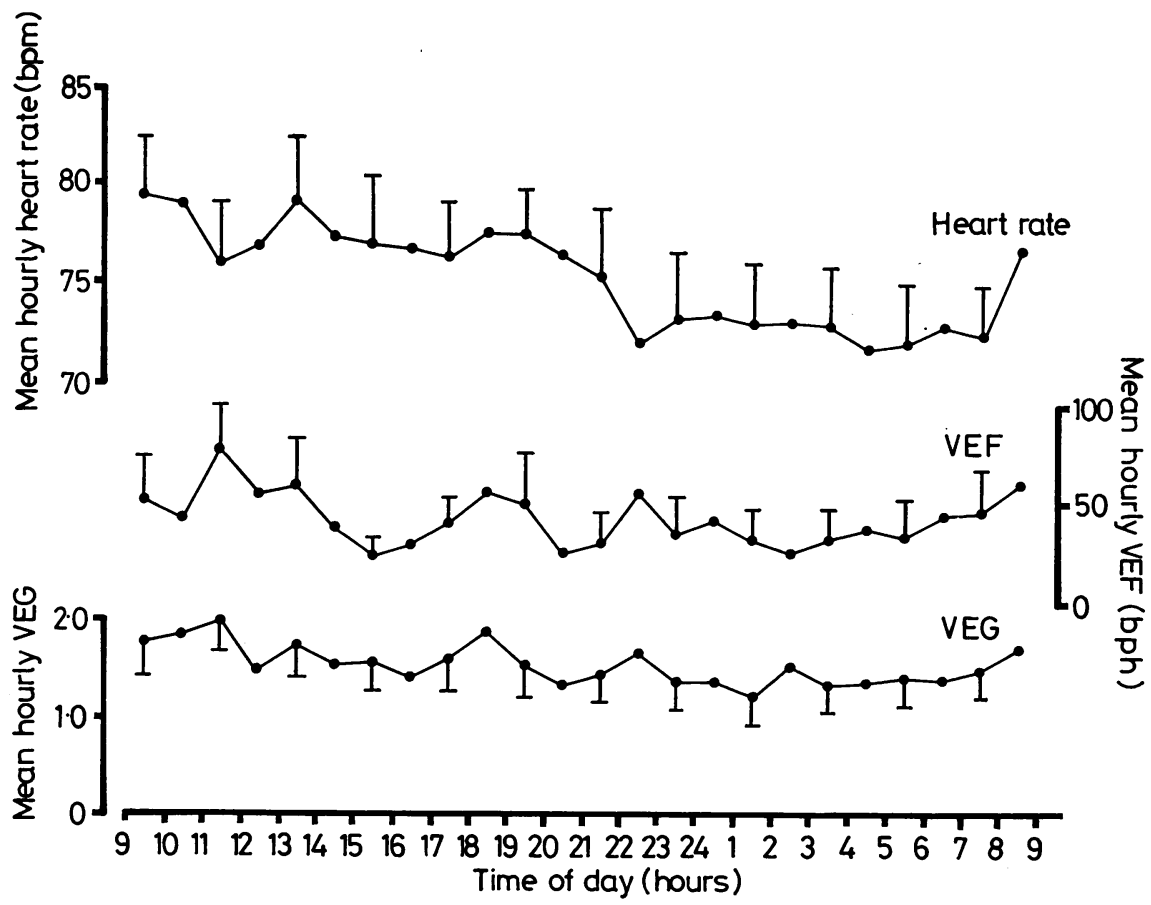

Fig. 2 Diurnal variation of heart rate, frequency of ventricular extrasystoles (VEF), and grade (severity) of ventricular arrhythmias (VEG) during home recordings (32 patients; bars represent SEM).

to 0600 hours $(72 \cdot 8 \pm 1 \cdot 2 \mathrm{bpm})$ was significantly lower than during the period 1200 to 1800 hours $(77.4 \pm 1.3$ bpm; $\mathrm{p}<0.001)$.

Although both frequency of ventricular extrasystoles and grade of ventricular arrhythmias tended to be lower during sleep the differences were not statistically significant (Fig. 1 and 2).

Particular attention was paid to changes at the reported time of waking up. The average heart rate during the hour of waking up $(76 \cdot 5 \pm 2 \cdot 4 \mathrm{bpm})$ was higher than that in any of the preceding three hours in $39(58.2 \%)$ of the recordings and significantly higher than that in the hour immediately before waking $(72 \cdot 9 \pm 2 \cdot 1 \mathrm{bpm} ; \mathrm{p}<0.01)$. The frequency of ventricular extrasystoles and grade of ventricular arrhythmias during the hour of waking were higher than in any of the preceding three hours in "only 19.4 per cent and 10.5 per cent of the recordings, respectively. The average frequency of ventricular extrasystoles during the hour of waking (21.5 \pm $11.6 \mathrm{bpm}$ ) was not significantly different from that in the hour before waking $(18.2 \pm 9.4 \mathrm{bpm} ; \mathrm{p}>0.05)$. The average grade of ventricular arrhythmias during the hour of waking $(0.95 \pm 1 \cdot 17)$ was similar to that in the preceding hour $(1.02 \pm 0.18 ; p>0.05)$. In many patients ventricular arrhythmias were

Table 2 Comparison of heart rate, frequency of ventricular extrasystoles, and grade of ventricular arrhythmias in hospital and home recordings (24 patients)

\begin{tabular}{|c|c|c|c|c|c|c|}
\hline \multirow[b]{2}{*}{$\begin{array}{l}\text { Heart rate (bpm) } \\
\text { Frequency of ventricular extrasystoles (bph) } \\
\text { Grade of ventricular arrhythmias }\end{array}$} & \multicolumn{3}{|c|}{$\begin{array}{lc}\text { Hospital } & \text { Home } \\
\text { day-time } & (1200-1800)\end{array}$} & \multicolumn{3}{|c|}{$\begin{array}{lc}\text { Hospital } & \text { Home } \\
\text { night-time } & (2400-0600)\end{array}$} \\
\hline & $\begin{array}{l}75 \cdot 0 \pm 1 \cdot 4 \\
21 \cdot 0 \pm 6 \cdot 5 \\
0.99 \pm 0 \cdot 11\end{array}$ & $\begin{array}{l}79 \cdot 8 \pm 1 \cdot 4 \\
50 \cdot 1 \pm 11 \cdot 2 \\
1 \cdot 63 \pm 0 \cdot 13\end{array}$ & $\begin{array}{l}\mathrm{p}<0.02 \\
\mathrm{p}<0.01 \\
\mathrm{p}<0.001\end{array}$ & $\begin{array}{l}73 \cdot 0 \pm 1 \cdot 3 \\
17 \cdot 8 \pm 5 \cdot 3 \\
1 \cdot 00 \pm 0 \cdot 12\end{array}$ & $\begin{aligned} 74 \cdot 8 & \pm 1 \cdot 4 \\
42 \cdot 7 & \pm 10 \cdot 4 \\
1 \cdot 52 & \pm 0 \cdot 13\end{aligned}$ & $\begin{array}{l}\text { NS } \\
p<0.05 \\
p<0.005\end{array}$ \\
\hline
\end{tabular}

Figures given are means $\pm \mathrm{SD}$.

Paired $t$ test.

NS, not significant. 
sporadic, with no extrasystoles occurring for several hours and then counts of several hundred in individual hours. A few patients had only one or two ventricular extrasystoles throughout each 24-hour period, whereas one patient had regular hourly counts of more than 1000. Eliminating this last patient from the analysis reduced the average frequency of ventricular extrasystoles but did not change the trends or differences.

\section{(3) COMPARISON OF HOME AND HOSPITAL RECORDINGS}

Matched recordings were obtained in 24 patients. Both heart rate and frequency of ventricular extrasystoles were raised at home compared with the hospital recording (Table 2). For heart rate the difference was only apparent during the day $(p<0.02)$ (Fig. 3). The early morning rise in heart rate occurred about two hours earlier in hospital (Fig. 3) than at home, a pattern which reflected the earlier time of waking in hospital $(0612 \pm 0030$ hours; mean $\pm S D$ ) as compared with home $(0753 \pm 0110$ hours). Frequency of ventricular extrasystoles and grade of ventricular arrhythmias throughout the 24 hours were higher at home than in hospital, both during the daytime $(p<0.01$ and $<0.001$, respectively) and also during sleep (p $<0.05$ and $<0.005$, respectively) (Table 2 , Fig. 4 and 5).

\section{(4) COMPARISON OF PERI-DISCHARGE RECORDINGS WITH THOSE MADE IN HOSPITAL AND AT HOME}

In 17 patients recordings were available from all three 24-hour periods. On the morning of the day of discharge (0900 to 1400 hours), before the patient left hospital, mean heart rate was significantly higher $(79.6 \pm 1.4 \mathrm{bpm})$ than the heart rate during the equivalent period of the hospital recordings $(73.8 \pm 1.4 \mathrm{bpm} ; \mathrm{p}<0.05)$, but was similar to that in the home recording $(81 \cdot 3 \pm 2.0 \mathrm{bpm} ; \mathrm{p}>0.05)$. After leaving hospital the heart rate in the peridischarge recordings was similar to that in the home recordings. There were no significant differences between the sleeping heart rate in the hospital, peri-discharge, and home recordings.

Mean frequency of ventricular extrasystoles on the morning of discharge $(63.0 \pm 25.0 \mathrm{bph})$ was significantly higher than during the equivalent period of the hospital recordings $(35.3 \pm 14.0 \mathrm{bph}$; $\mathrm{p}<0.02)$ but was similar to the home recordings $(74.0 \pm 20.0 \mathrm{bph} ; \mathrm{p}>0.05)$. In the period after arrival home (1400 to 0900 hours) the mean frequency of ventricular extrasystoles on the day of

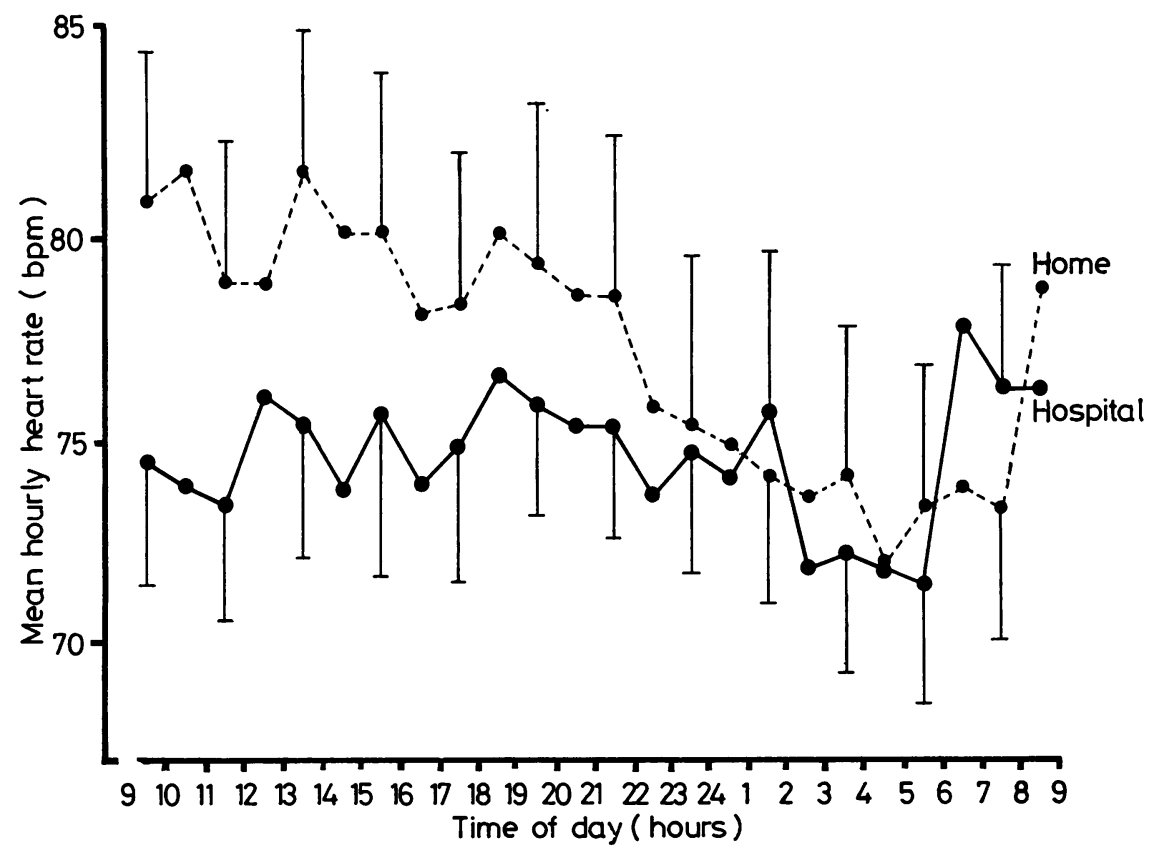

Fig. 3 Comparison of mean hourly heart rate in hospital and at home (24 patients; bars represent SEM). 


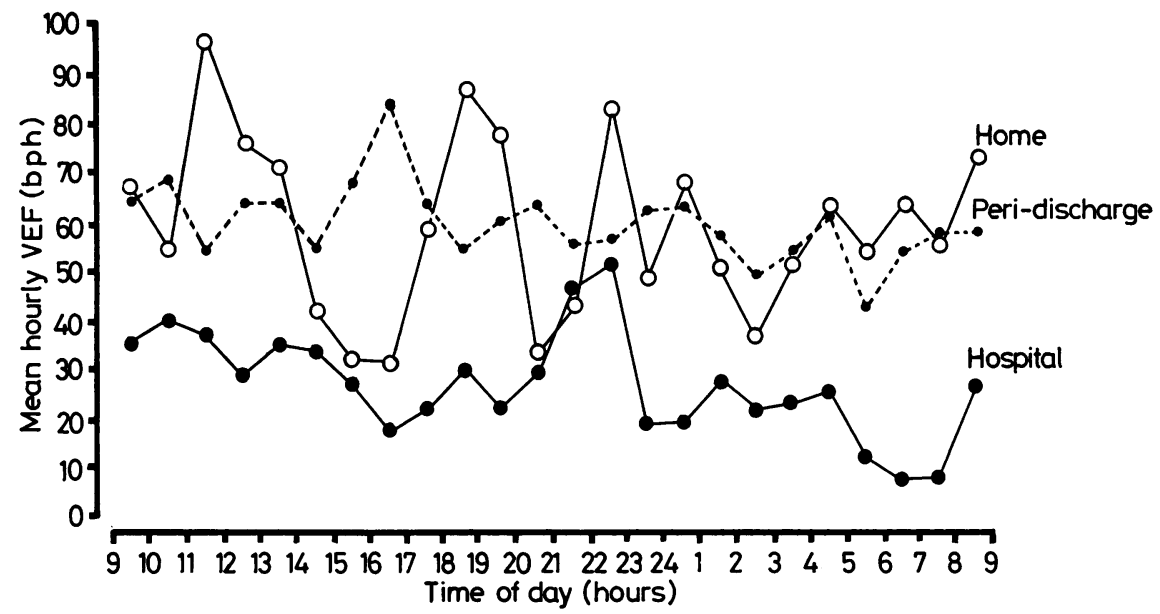

Fig. 4 Comparison of mean hourly frequency of ventricular extrasystoles (VEF) during hospital, peri-discharge, and home recordings (17 patients).

discharge $(60.5 \pm 10.7 \mathrm{bph})$ was higher than in the corresponding period of the hospital recordings $(27.1 \pm 5.0 \mathrm{bph} ; \mathrm{p}<0.001)$ but was again similar to that in the home recordings $(59.5 \pm 7.9 \mathrm{bph}$; $\mathrm{p}>0.05$ ) (Fig. 4). The changes in grade of ventricular arrhythmias were similar. On the morning of discharge (0900 to 1400 hours) the mean grade was higher $(1.31 \pm 0.18)$ than in the hospital recordings $(1.00 \pm 0.16 ; \mathrm{p}<0.05)$ but was lower than in the equivalent period of the home recording $(1.81 \pm 0.18 ; \mathrm{p}<0.005)$. After discharge $(1400$ to 0900 hours) the mean grade of ventricular arrhythmias in the peri-discharge recording $(1.46 \pm 0.09)$ continued to be higher than in the hospital recording

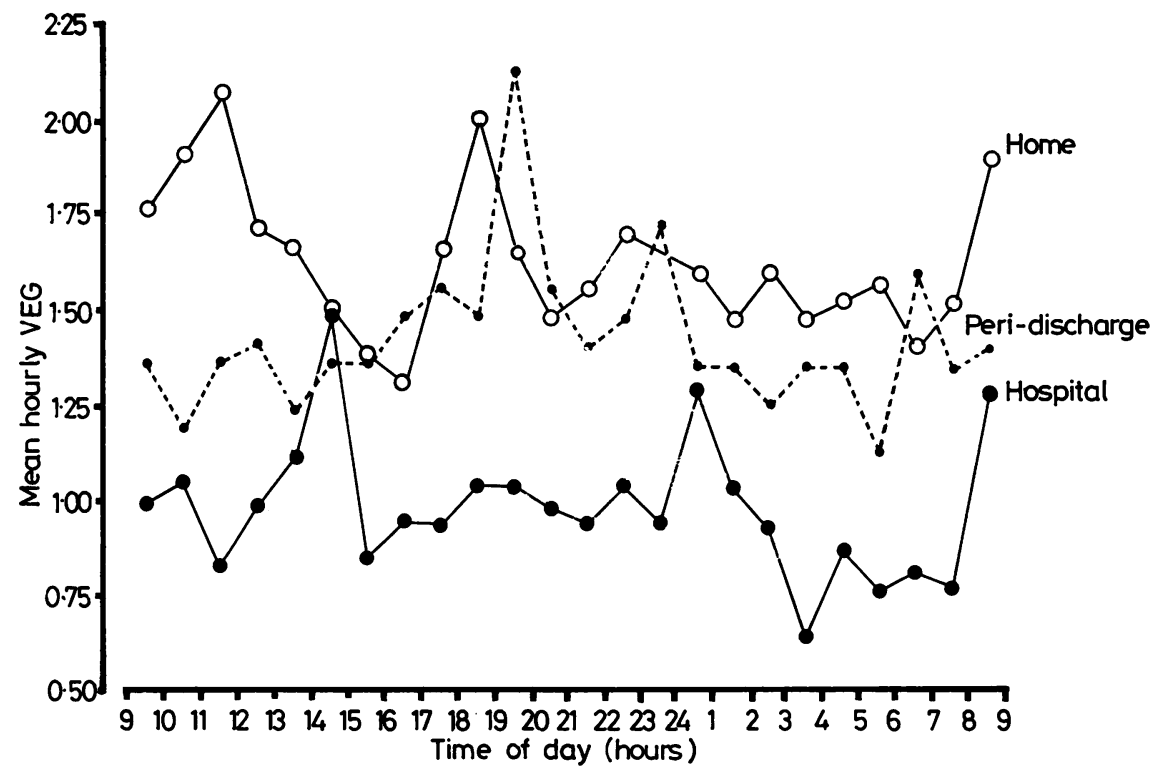

Fig. 5 Comparison of mean hourly grade (severity) of ventricular arrhythmias (VEG) during hospital, peri-discharge, and home recordings (17 patients). 
$(0.96 \pm 0.08 ; \mathrm{p}<0.001)$ but was similar to that seen in the later home recording ( $1.59 \pm 0.09$; p $>0.05$ ) (Fig. 5).

\section{(5) CHANGES AT TIME OF DISCHARGE FROM HOSPITAL}

Because heart rate and ventricular arrhythmias on the morning of the day of discharge (0900 to 1400 hours) were raised in comparison with the corresponding period 48 hours earlier (hospital recording), it was decided to examine the relation of this rise to the time of discharge from hospital. Peri-discharge recordings were available from 28 patients. The mean time of discharge was $1445 \pm$ 0207 hours. Because the individual times of discharge varied, the recordings were matched for the hour in which the journey home took place. In each recording the hour in which the patient left hospital was termed the discharge hour (0) and the changes in the preceding and succeeding five-hour periods were analysed. One patient had less than five hours' recording available before discharge and was therefore excluded.

When the recordings were matched in this way an upward trend in heart rate, frequency of ventricular extrasystoles, and grade of ventricular arrhythmias was apparent in the three hours before discharge, but only the changes in heart rate reached statistical significance (Fig. 6). Overall the average heart rate in the three hours before discharge $(77.7 \pm 1.8 \mathrm{bpm})$ was significantly higher than in the three hours after discharge $(74.3 \pm 1.5$ bpm; $\mathrm{p}<0.001)$. The corresponding values for frequency of ventricular extrasystoles were $3 \cdot 6 \pm 1 \cdot 0$ and $6 \cdot 1 \pm 2.8(p>0.05)$, and for grade of ventricular arrhythmias they were $0.95 \pm 0.17$ and $0.85 \pm 0.14$ $(\mathrm{p}>0.05)$, respectively.

The mean heart rate during the hour of discharge was higher than in any of the preceding three hours

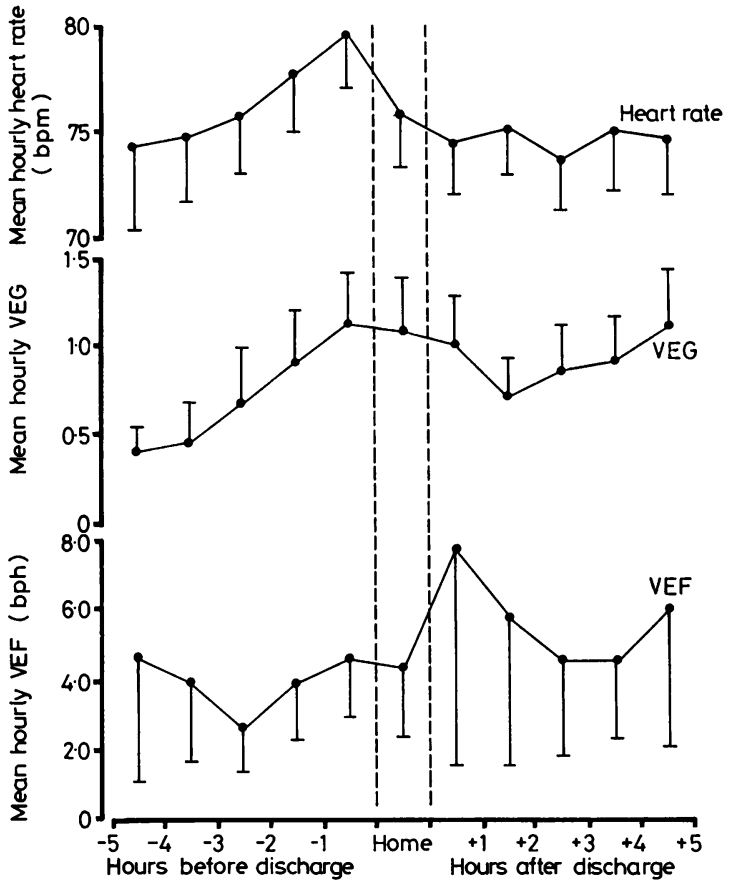

Fig. 6 Changes in heart rate, frequency of ventricular extrasystoles (VEF), and grade (severity) of ventricular arrhythmias (VEG) during the peri-discharge period (27 patients; bars represent SEM).

in six patients $(35.3 \%)$, higher than in any of the succeeding three hours in $12(70.6 \%)$, and higher than both periods in four $(23.5 \%)$. The highest average heart rate $(79.7 \pm 3.1 \mathrm{bpm})$ occurred in the hour before discharge and was significantly higher than that during the discharge hour $(75.0 \pm 2.8$ $\mathrm{bpm} ; \mathrm{p}<0.01)$. Average heart rate during the discharge hour was also lower than the mean value of

Table 3 Incidence and severity of specific arrhythmias at different stages of convalescence after acute myocardial infarction

\begin{tabular}{|c|c|c|c|c|c|c|c|c|c|c|c|c|c|c|c|c|c|c|}
\hline \multirow[b]{3}{*}{$\begin{array}{l}\text { Hospital recording } \\
\quad(n=34)\end{array}$} & \multicolumn{3}{|c|}{$\begin{array}{l}\text { Heart rate } \\
\text { (bpm) }\end{array}$} & \multirow{2}{*}{\multicolumn{3}{|c|}{$\begin{array}{l}\text { Supra- } \\
\text { ventricular } \\
\text { arrhythmias } \\
\text { SVEs SVT } A F\end{array}$}} & \multicolumn{6}{|c|}{ Ventricular arrhythmias } & \multicolumn{6}{|c|}{$\begin{array}{l}\text { Maximum grade of ventricular } \\
\text { arrhythmia }\end{array}$} \\
\hline & \multirow{2}{*}{$\begin{array}{c}<60 \\
10 \\
(29)\end{array}$} & \multicolumn{2}{|c|}{$>100>120$} & & & & \multirow{2}{*}{$\begin{array}{c}V E s \\
34 \\
(100)\end{array}$} & \multicolumn{2}{|c|}{$F>1 B g$} & \multirow{2}{*}{$\frac{P}{9}$} & \multirow{2}{*}{ 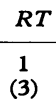 } & \multirow{2}{*}{$\frac{V T}{(3)}$} & \multirow{2}{*}{ 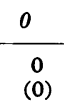 } & \multirow{2}{*}{$\frac{1}{10}$} & \multirow{2}{*}{$\begin{array}{c}2 \\
0 \\
(0)\end{array}$} & \multirow{2}{*}{$\frac{3}{11}$} & \multirow{2}{*}{$\frac{4}{12}$} & \multirow{2}{*}{$\frac{5}{1}$} \\
\hline & & $\begin{array}{c}12 \\
(35)\end{array}$ & $\begin{array}{c}9 \\
(26)\end{array}$ & $\begin{array}{c}19 \\
(56)\end{array}$ & $\begin{array}{c}9 \\
(26)\end{array}$ & $\begin{array}{c}4 \\
(12)\end{array}$ & & $\begin{array}{c}22 \\
(65)\end{array}$ & $\begin{array}{c}8 \\
(24)\end{array}$ & & & & & & & & & \\
\hline $\begin{array}{l}\text { Discharge recording } \\
(\mathbf{n}=28)\end{array}$ & $\begin{array}{c}8 \\
(28)\end{array}$ & $\begin{array}{c}11 \\
(39)\end{array}$ & $\begin{array}{c}5 \\
(18)\end{array}$ & $\begin{array}{c}15 \\
(44)\end{array}$ & $\begin{array}{c}6 \\
(18)\end{array}$ & $\begin{array}{l}3 \\
(9)\end{array}$ & $\begin{array}{c}25 \\
(89)\end{array}$ & $\begin{array}{l}18 \\
(64)\end{array}$ & $\begin{array}{c}9 \\
(32)\end{array}$ & $\begin{array}{c}7 \\
(25)\end{array}$ & $\begin{array}{l}1 \\
(4)\end{array}$ & $\begin{array}{c}3 \\
(11)\end{array}$ & $\begin{array}{c}3 \\
(11)\end{array}$ & $\begin{array}{c}5 \\
(17)\end{array}$ & $\begin{array}{c}0 \\
(0)\end{array}$ & $\begin{array}{c}8 \\
(29)\end{array}$ & $\begin{array}{l}11 \\
(39)\end{array}$ & $\begin{array}{l}1 \\
(4)\end{array}$ \\
\hline
\end{tabular}

Figures in parentheses are percentages.

$\mathrm{n}$, number of patients; SVEs, supraventricular extrasystoles; SVT, supraventricular tachycardia; AF, atrial fibrillation; VEs, ventricular extrasystoles; $\mathrm{F}>1$, more than one focus of VEs; $\mathrm{Bg}$, bigeminy; $\mathrm{P}$, pairs of VEs; RT, R-on-T phenomenon; VT, ventricular tachycardia. 
the hours immediately before and after when these were combined $(76.6 \pm 2.9)$ but the difference was not statistically significant $(p>0.05)$.

The frequency of ventricular extrasystoles during the hour of discharge was higher than in any of the preceding three hours in five $(18.5 \%)$ patients, the succeeding three hours in six $(22.2 \%)$, and both periods in only two $(7 \cdot 4 \%)$. For grade of ventricular arrhythmias the corresponding figures were four $(14.8 \%)$, three $(11.1 \%)$, and two $(7.4 \%)$ patients, respectively. The average frequency of ventricular extrasystoles and grade of ventricular arrhythmias during the discharge hour were both lower than the means of the immediately preceding and succeeding hours combined, but the differences were not statistically significant.

\section{(6) INCIDENCE OF SPECIFIC ARRHYTHMIAS}

The frequencies of individual arrhythmias during the three stages of recording are shown in Table 3. All of the patients had ventricular arrhythmias in at least one recording and 75 per cent had supraventricular arrhythmias. In the hospital recording 65 per cent of patients had more than one focus of ventricular extrasystoles and, overall, "complicated" ventricular arrhythmias (Lown grade 3) were present in 70 per cent. Similar findings were present in the home recordings, with 78 per cent of patients having "complicated" ventricular arrhythmias, including four (13\%) with ventricular tachycardia. In none of the recordings did ventricular fibrillation, heart block, or extreme bradycardia (heart rate $<45 \mathrm{bpm}$ ) occur. During the journey home 14 $(52 \%)$ patients had ventricular arrhythmias, with bigeminy in five $(19 \%)$, pairs in two $(7 \%)$, and ventricular tachycardia in one (4\%). Supraventricular extrasystoles occurred in seven $(26 \%)$, with supraventricular tachycardia in two $(8 \%)$. In every case similar arrhythmias were present in two or three of the recordings.

(7) FACTORS RELATED TO INCIDENCE OF ARRHYTHMIAS DURING CONVALESCENT PERIOD

None of the following factors was found to be predictive of arrhythmias, either in the convalescent period as a whole or at the time of discharge: age, sex, personality type, smoking habits, peak aspartate aminotransferase, previous history of acute myocardial infarction or angina, minimum blood pressure, maximum heart rate, or presence of heart failure. In particular, there was no significant relation between the occurrence of ventricular tachycardia or ventricular fibrillation in the coronary care unit and ventricular arrhythmias in this early convalescent phase. The average convalescent frequency of ventricular extrasystoles $(11 \cdot 8 \pm 11 \cdot 2$ bpm) in the five patients who had suffered very frequent ventricular extrasystoles in the coronary care unit was similar to that in the 28 patients in whom only occasional ventricular extrasystoles had been noted $(10 \cdot 0 \pm 4 \cdot 7 \mathrm{bpm})$. Convalescent heart rate was, however, positively correlated with heart rate during the acute phase $(\mathrm{r}=0.6163 ; \mathrm{p}<0.001)$ and so was grade of ventricular arrhythmias $(r=0.4700 ; p<0.01)$. In addition, convalescent heart rate was positively correlated with both convalescent frequency of ventricular extrasystoles $(r=0.2415 ; p<0.05)$ and grade of ventricular arrhythmias $(r=0.2982 ; p<0.05)$. Peak serum aspartate aminotransferase had no significant correlation with convalescent heart rate, frequency of ventricular extrasystoles, or grade of ventricular arrhythmias. The frequency of ventricular extrasystoles in the five patients taking anxiolytic drugs at the time of discharge was significantly higher than in those not taking these drugs $(p<0.025)$ but this did not apply to the grade of ventricular arrhythmias $(\mathrm{p}>0.05)$.

\section{(8) EFFECT OF BETA-BLOCKING DRUGS}

Six patients were receiving beta-blocking drugs. The mean convalescent heart rate in this group $(72.1 \pm 1.3 \mathrm{bpm})$ was lower than in those patients not taking beta-blockers $(78.3 \pm 2.8)(p<0.05)$ but there were no significant differences in frequency of ventricular extrasystoles or grade of ventricular arrhythmias. The differences between recordings made at different times and the changes on the day of discharge were qualitatively similar to those reported above but tended to be smaller. Betablocking agents did not prevent significant rises in heart rate, frequency of ventricular extrasystoles, and grade of ventricular arrhythmias on the morning of the day of discharge compared with the hospital recording.

\section{(9) SYMPTOMS AND ACTIVITY OF PATIENTS} Thirty-eight $(86.4 \%)$ of the patients travelled home by car accompanied by at least one relative. Only 13 $(30 \%)$ were thought to show any anxiety on the morning of discharge and only nine $(21 \%)$ admitted to any. After arrival home 69 per cent of the patients went freely up and down stairs and 13 per cent ventured out of doors. During the home recording $26(59 \cdot 1 \%)$ patients reported some symptoms, including palpitation, unrelated to any electrocardiographic abnormality. Heart rates of up to $140 \mathrm{bpm}$ and ventricular extrasystoles of more than $1000 \mathrm{bph}$ were tolerated without symptoms. 


\section{Discussion}

The acute phase of myocardial infarction is frequently complicated by sudden death often preceded by a period of increased ventricular extrasystoles. ${ }^{12}$ Less attention has been given to the convalescent phase, when arrhythmias and sudden death may also occur. In one series ${ }^{17} 6.3$ per cent of patients discharged from the coronary care unit later died in hospital, with all except one death occurring within three weeks of infarction. Lund$\operatorname{man}^{18}$ found a 3 to 12 per cent mortality in the second week after infarction and Gorfinkel et al. ${ }^{5}$ described potentially lethal arrhythmias in 3 per cent of patients after discharge from the coronary care unit. Late in-hospital ventricular fibrillation has been reported in 3 per cent of patients with 60 per cent mortality ${ }^{2}$ and late in-patient ventricular tachycardia has been observed in 2 to 8 per cent of patients. ${ }^{419}$ This increased risk is not limited to the hospital phase. Gelson et al. ${ }^{9}$ reported 4 per cent of patients dying within one week of hospital discharge and 7 per cent within six weeks. Hutter et al. ${ }^{20}$ reported a 4 to 7 per cent mortality in the first six months. These last two studies were favourably biased by the exclusion of complicated cases. Moss et al. ${ }^{8}$ found 4 per cent of patients died within four months of discharge, and 67 per cent of deaths within the first six months were thought to be primarily arrhythmic. ${ }^{10}$ Because the presence of ventricular extrasystoles in a resting electrocardiogram may be associated with increased mortality ${ }^{2122}$ and, in the presence of ischaemic heart disease, with sudden death, ${ }^{23}{ }^{24}$ it was logical to attempt to relate the incidence of ventricular extrasystoles in the convalescent period of acute myocardial infarction to long-term prognosis. Moss et al. ${ }^{8}$ found that patients with "complicated" ventricular extrasystoles before discharge had an increased mortality at four months but not in the first year as a whole. A similar association between pre-discharge ventricular extrasystoles and seven-month mortality was described by Schulze et al. ${ }^{12}$ With the increased use of 24-hour electrocardiographic monitoring, however, it has became clear that ventricular extrasystoles are common after acute myocardial infarction, occurring in up to 86 per cent of patients with stable ischaemic heart disease and even in 67 per cent of subjects without heart disease. ${ }^{25}$ The actual frequency and grade of ventricular extrasystoles depends upon the duration and numbers of the electrocardiograms $^{51626}$ and whether "activities" like sleep and exercise are included. ${ }^{616} 27$ In the late hospital phase of acute myocardial infarction the presence of ventricular extrasystoles has been reported in up to 93 per cent of patients, ${ }^{7}$ with up to 61 per cent having "complicated" ventricular extrasystoles. ${ }^{28}$

The findings of the present study suggest even higher levels, with 100 per cent incidence of ventricular extrasystoles and 85.7 per cent "complicated" ventricular extrasystoles. This higher level was probably seen because only complete 24hour recordings were accepted and the total duration of recording time in each patient was up to 72 hours. Though ventricular extrasystoles tended to be sporadic there was a high degree of correlation in the incidence of ventricular extrasystoles and, to a lesser extent, the grade of ventricular extrasystoles between different tapes in individual patients. The degree of reproducibility was higher than has been suggested previously. ${ }^{29}$ The best correlations were between the hospital and peridischarge recordings and were least good between the hospital and home recordings. Though the frequency and grade of ventricular extrasystoles were correlated with each other, the grade often changed without much change in the numbers of ventricular extrasystoles. The frequency and grade of ventricular extrasystoles were positively correlated with heart rate. One possible mechanism would be through the size of infarction and presence of left ventricular dysfunction, ${ }^{30}{ }^{31}$ though it is surprising that ventricular extrasystoles were not related to peak serum aspartate aminotransferase, but neither was heart rate. Furthermore, ventricular extrasystoles were not related to the presence of overt heart failure or to the site of infarction.

There was no correlation between persistent ventricular extrasystoles during the acute phase of myocardial infarction and the incidence of ventricular extrasystoles in the convalescent phase, a finding which has been noted previously. ${ }^{3}{ }^{32}$ In particular, ventricular fibrillation in the acute phase did not predispose to excessive ventricular extrasystoles later. Complicated ventricular extrasystoles may first appear during the convalescent period, either in hospital ${ }^{32}$ or after discharge. ${ }^{8}$

At all three stages of early convalescence there was a diurnal variation in heart rate corresponding to that reported for patients without ischaemic heart disease. ${ }^{33}$ Blood pressure is known to follow a similar pattern ${ }^{33}$ and the early morning rise of these two may predispose to angina ${ }^{34}$ or morning infarction..$^{35}$ In none of our patients did either of these occur. There have been few reports of diurnal variation in ventricular extrasystoles. Lown and Wolf ${ }^{16}$ and Rehnqvist ${ }^{6}$ suggested that ventricular ectopic activity increased during sleep, but Lown et $a .^{36}$ found that ventricular extrasystoles decreased during sleep in about three-quarters of patients with ischaemic heart disease and often 
in patients resistant to treatment with antiarrhythmic drugs. In a few patients an increase in ventricular extrasystoles occurred on waking, a phenomenon previously noted in patients in the acute phase of myocardial infarction. ${ }^{37}$ Our results suggest that, at least in the early convalescent phase of myocardial infarction, diurnal variation in ventricular extrasystoles is relatively uncommon and an early morning rise the exception rather than the rule. This would not be too surprising because the cardiovascular changes during sleeping and waking are the result more of changes in parasympathetic than sympathetic activity. ${ }^{38}$

The main purpose of this study was to evaluate the "stress" effects of hospital discharge on heart rate and ventricular extrasystoles. This might come from at least three directions; firstly, as a consequence of leaving the security of hospital with its potentially life-saving equipment and expertise ${ }^{13}$; secondly, travelling home by "car" which can lead to increases in heart rate and ventricular extrasystoles in normal subjects ${ }^{39}$ as well as those with ischaemic heart disease $\mathrm{e}^{40}$ and, thirdly, with the need to readjust to home life and the future. Our results showed that heart rate and ventricular extrasystoles were significantly increased on the morning of the day of discharge and that they increased further up to the time of leaving hospital. Though this might have been because of increased physical activity this is unlikely because the level of activity was not increased according to our observations, nor did the patients report increased activity in the "diary" cards. Furthermore, there was no increase in movement artefact in their recordings. Finally, at the time of discharge, when physical activity would be expected to increase, there was an overall fall in heart rate, which continued after arrival home, at which time the patients did report increased physical activity. The changes in frequency of ventricular extrasystoles were less sustained than those in the grade of extrasystoles, which remained evident after arrival home and also 48 hours later in the home recording. There was no tendency for heart rate or ventricular extrasystoles to increase during the journey home. Though arrhythmias were common at this time they were always present at other times. In particular, patients in whom ventricular fibrillation or frequent ventricular extrasystoles had been a feature of the acute phase and those taking beta-blocking drugs did not behave differently from the rest of the group..$^{28} 32$ Patients taking anxiolytic drugs had significantly higher levels of frequency of ventricular extrasystoles but not of grade of ventricular extrasystoles. This may well be a chance finding in a small group, though the effect of heightened anxiety (requiring treatment) cannot be excluded. A minority of patients showed evidence of anxiety before discharge, but the majority seemed relieved and optimistic at the prospect of going home. Possibly relatives become more stressed than patients, but we did not examine this. Though the patients appeared more relaxed in their homes, heart rate and frequency and grade of ventricular extrasystoles were all significantly higher during the home recordings than during those made in hospital. This would be unlikely to be a result of increased physical activity ${ }^{27}{ }^{41}$ because the difference in the frequency of ventricular extrasystoles was most obvious during sleep. Increased levels of circulating catecholamines may have been responsible ${ }^{4243}$ but these were not monitored. Whatever the mechanism, patients after acute myocardial infarction are more at risk from serious ventricular extrasystoles 48 hours after hospital discharge than $\mathbf{4 8}$ hours before it or at the time of discharge. The prognostic importance of this finding is not clear. Winkle et al. ${ }^{44}$ and Anderson et al.$^{32}$ have suggested that ventricular tachycardia in the convalescent phase of acute myocardial infarction does not change prognosis, but reduced survival has been reported elsewhere. ${ }^{4} 3145$

This study shows that ventricular extrasystoles are almost universal in the early convalescent phase of acute myocardial infarction and that they are increased 48 hours after discharge from hospital. The actual time of leaving hospital and the journey home do not appear to be periods of heightened risk from serious cardiac arrhythmias. With the trend, however, towards even earlier discharge from hospital after acute myocardial infarction the above investigations may need further re-examination.

\section{References}

1 Henning R, Lundman T. Swedish co-operative CCU study part I: a description of the early stage. Acta Med Scand 1975; 586, suppl: 1-64.

2 Lie KI, Liem KL, Schuilenburg RM, David GK, Durrer D. Early identification of patients developing late in-hospital ventricular fibrillation after discharge from the coronary care unit. Am $f$ Cardiol 1978; 41: 674-7.

3 Moss AJ, Schnitzler R, Green R, DeCamilla J. Ventricular arrhythmias three weeks after acute myocardial infarction. Ann Intern Med 1971; 75: $837-41$.

4 Vismara LA, DeMaria AN, Hughes JL, Mason DT, Amsterdam EA. Evaluation of arrhythmias in the late hospital phase of acute myocardial infarction com- 
pared to coronary care unit ectopy. Br Heart $\mathcal{f} 1975$; 37: 598-603.

5 Gorfinkel HJ, Kercher L, Lindsay J Jr. Electrocardiographic radiotelemetry in the early recuperative period of acute myocardial infarction. Chest 1976; 69: $158-63$.

6 Rehnqvist N. Ventricular arrhythmias prior to discharge after acute myocardial infarction. Eur $\mathcal{f}$ Cardiol 1976; 4: 63-70.

7 De Soyza N, Murphy ML, Bissett JK, Kane JJ. Detecting ventricular arrhythmia after myocardial infarction: comparison of Holter monitoring and treadmill exercise. South Med f 1977; 70: 403-4.

8 Moss AJ, DeCamilla JJ, Davis HP, Bayer L. Clinical significance of ventricular ectopic beats in the early post-hospital phase of myocardial infarction. Am $\mathcal{F}$ Cardiol 1977; 39: 635-40.

9 Gelson ADN, Carson PHM, Tucker HH, Phillips R, Clarke M, Oakley GDG. Course of patients discharged early after myocardial infarction. $\mathrm{Br} \mathrm{Med} \mathcal{F}$ 1976; i: 1555-8.

10 Moss AJ, DeCamilla JJ, Davis H. Cardiac death in the first six months after myocardial infarction: potential for mortality reduction in the early posthospital period. Am f Cardiol 1977; 39: 816-20.

11 Moss AJ, DeCamilla JJ, Meitlowski W, Greene WA, Goldstein S, Locksley R. Prognostic grading and significance of ventricular premature beats after recovery from myocardial infarction. Circulation 1975; 52, suppl 3: 204-10.

12 Schulze RA Jr, Strauss HW, Pitt B. Sudden death in the year following myocardial infarction. Relation to ventricular premature contractions in the late hospital phase and left ventricular ejection fraction. Am f Med 1977; 62: 192-9.

13 Dellipiani AW, Cay EL, Phillip AE, et al. Anxiety after a heart attack. Br Heart $\mathcal{f} 1976$; 38: $752-7$.

14 Malik MAO. Emotional stress as a precipitating factor in sudden deaths due to coronary insufficiency. f Forensic Sci 1973; 18: 47-52.

15 Rosenman RH, Friedman M. Neurogenic factors in pathogenesis of coronary heart disease. Med Clin North Am 1974; 58: 269-79

16 Lown B, Wolf $M$. Approaches to sudden death from coronary heart disease. Circulation 1971; 44: 130-42.

17 Spracklen FHN, Kimerling JJ, Besterman EMM, Litchfield JW. Use of lignocaine in treatment of cardiac arrhythmias. $\mathrm{Br}$ Med $\mathcal{F}$ 1968; i: 89-91.

18 Lundman T. Short and long term prognosis of patients with acute myocardial infarction (AMI) and prediction of sudden deaths. Forensic Sci 1976; 8: 77-87.

19 De Soyza N, Bennett FA, Murphy ML, Bissett JK, Kane JJ. The relationship of paroxysmal ventricular tachycardia complicating the acute phase and ventricular arrhythmia during the late hospital phase of myocardial infarction to long-term survival. $A m \mathcal{F}$ Med 1978; 64: 377-81.

20 Hutter AM Jr, Sidel VW, Shine KI, De Sanctis RW. Early hospital discharge after myocardial infarction.
N Engl f Med 1973; 288: 1141-4.

21 Chiang BN, Perlman LV, Ostrander LD Jr, Epstein FH. Relationship of premature systoles to coronary heart disease and sudden death in the Tocumseh epidemiological study. Ann Intern Med 1969; 70: 1159-66.

22 Hinkle LE Jr, Carver ST, Stevens $M$. The frequency of asymptomatic disturbances of cardiac rhythm and conduction in middle-aged men. Am $\mathcal{f}$ Cardiol 1969; 24: 629-50.

23 Weiss AN, Jobe CL, Gordon T, Lange PH, Frommer PL. Relationship of premature ventricular contractions and left ventricular hypertrophy to sudden cardiac death (abstract). Circulation 1969; 39, suppl 3: 213.

24 Fisher FD, Tyroler HA. Relationship between ventricular premature contractions on routine electrocardiography and subsequent sudden death from coronary heart disease. Circulation 1973; 47: 712-9.

25 Calvert A, Lown B, Gorlin R. Ventricular premature beats and anatomically defined coronary heart disease. Am F Cardiol 1977; 39: 627-34.

26 Tabatznik B. Ambulatory monitoring in the late postmyocardial infarction period. Postgrad Med $\mathcal{F}$ 1976; 52, suppl 7: 56-9.

27 Jelinek MV, Lown B. Exercise stress testing for exposure of cardiac arrhythmia. Prog Cardiovasc Dis 1974; 16: 497-522.

28 Rehnqvist N, Lundman T, Sjögren A. Prognostic implications of ventricular arrhythmias registered before discharge and one year after acute myocardial infarction. Acta Med Scand 1978; 204: 203-9.

29 Morganroth J, Michelson EL, Horowitz LN, Josephson ME, Pearlman AS, Dunkman WB. Limitations of routine long-term electrocardiographic monitoring to assess ventricular ectopic frequency. Circulation 1978; 58: 408-14.

30 Schulze RA Jr, Rouleau J, Rigo P, Bowers S, Strauss HW, Pitt B. Ventricular arrhythmias in the late hospital phase of acute myocardial infarction. Relation to left ventricular function detected by gated cardiac blood pool scanning. Circulation 1975; 52: 1006-11.

31 Federman J, Whitford JA, Anderson ST, Pitt A. Incidence of ventricular arrhythmias in first year after myocardial infarction. Br Heart $\mathcal{f}$ 1978; 40: 1243-50.

32 Anderson KP, DeCamilla J, Moss AJ. Clinical significance of ventricular tachycardia ( 3 beats or longer) detected during ambulatory monitoring after myocardial infarction. Circulation 1978; 57: 890-7.

33 Millar-Craig MW, Bishop CN, Raftery EB. Circadian variation of blood-pressure. Lancet 1978; i: 795-7.

34 Littler WA, Honour AJ, Sleight P, Stott FD. Direct arterial pressure and the electrocardiogram in unrestricted patients with angina pectoris. Circulation 1973; 48: 125-34.

35 Myers A, Dewar HA. Circumstances attending 100 sudden deaths from coronary artery disease with coroner's necropsies. Br Heart f 1975; 37: 1133-43. 
36 Lown B, Tykocinski M, Garfein A, Brooks P. Sleep and ventricular premature beats. Circulation 1973; 48: 691-701.

37 Smith R, Johnson L, Rothfeld D, Zir L, Tharp B. Sleep and cardiac arrhythmias. Arch Intern Med 1972; 130: 751-53.

38 Baust W, Bohnert B. The regulation of heart rate during sleep. Exp Brain Res 1969; 7: 169-80.

39 Taggart $P$, Gibbons D, Somerville W. Some effects of motor-car driving on the normal and abnormal heart. $\mathrm{Br}$ Med f 1969; iv: 130-4.

40 Littler WA, Honour AJ, Sleight P. Direct arterial pressure and electrocardiogram during motor car driving. $\mathrm{Br}$ Med F 1973; ii: 273-7.

41 Goldschlager N, Cake D, Cohn K. Exercise-induced ventricular arrhythmias in patients with coronary artery disease. Their relation to angiographic findings. Am F Cardiol 1973; 31: 434-40.
42 Lepeschkin E, Marchet H, Schroeder G, Wagner R, Silva $P$ de PE, Raab W. Effect of epinephrine and norepinephrine on the electrocardiogram of 100 normal subjects. Am F Cardiol 1960; 5: 594-603.

43 McDonald L, Baker C, Bray C, McDonald A, Restieaux N. Plasma-catecholamines after cardiac infarction. Lancet 1969; ii: 1021-3.

44 Winkle RA, Derrington DC, Schroeder JS. Characteristics of ventricular tachycardia in ambulatory patients. Am f Cardiol 1977; 39: 487-92.

45 Kotler MN, Tabatznik B, Mower MM, Tominaga S. Prognostic significance of ventricular ectopic beats with respect to sudden death in the late post infarction period. Circulation 1973; 47: 959-66.

Requests for reprints to $\mathrm{Dr} G \mathrm{~W}$ Morrison, Department of Cardiovascular Studies, The University, Leeds LS2 9JJ. 